\title{
SISTEM INFORMASI INDUSTRI KECIL MENENGAH PEMERINTAHAN KABUPATEN BOYOLALI
}

\author{
Rahayuning Putri Mahardikawati ${ }^{* 1}$, Nurgiyatna ${ }^{2}$ \\ 1,2Teknik Informatika (Fakultas Komunikasi dan Informatika, Universitas Muhammadiyah Surakarta) \\ Email: ${ }^{* 1} 1200160107 @$ student.ums.ac.id, ${ }^{2}$ N.Nurgiyatna @ ums.ac.id
}

(Naskah masuk: 06 Juli 2020, diterima untuk diterbitkan: 12 Juli 2020)

\begin{abstract}
Abstrak
Kabupaten Boyolali adalah salah satu kabupaten dari 35 Kabupaten/Kota di Provinsi Jawa Tengah yang proinvestasi dan memiliki kurang lebih unit yang terdiri dari industri, mikro, kecil dan menengah. Kondisi saat ini, pengelolaan Indutri Kecil Menengah Pemerintah Kabupaten Boyolali masih melakukkan pendataan secara konvensional. Meskipun jarak tempuh yang jauh, Dinas Perdagangan dan Perindustrian harus merekap data dengan cara mendatangi setiap kecamatan-kecamatan di Kabupaten Boyolali. Selain itu, belum adanya media informasi Industri Kecil Menengah Kabupaten Boyolali yang dapat diakses oleh masyarakat umum. Penelitian ini bertujuan membuat Sistem Informasi Industri Kecil Menengah Pemerintahan Kabuoaten Boyolali Berbasis Website untuk memudahkan dinas mendapatkan data-data industri, masyarakat umum yang memiliki industri dapat mendaftar secara online agar dapat mengajukan bantuan secara online, serta menjadikan sistem ini sebagai media promosi industri. Sistem Informasi ini menggunakan framework laravel dengan bahasa pemrograman PHP, dan database MySQL. Metode pengembangan perangkat lunak yang digunakan adalah waterfall, dalam perancangan dan pembuatan meliputi tahap analisis kebutuhan, desain aplikasi, pengkodingan aplikasi, pengujian, dan perawatan. Berdasarkan hasil uji black box, sistem mempunyai menu kelola data industri, kelola data member, kelola rekap industri, kelola pengajuan bantuan serta sistem ini sebagai sarana media informasi seputar Industri Kecil Menengah. Berdasarkan pengujian SUS, sistem mendapat skor 70,58 yang berarti sistem termasuk dalam kategori baik dan dapat diterima.
\end{abstract}

Kata kunci: black box, industri kecil menengah, Kabupaten Boyolali, sistem Informasi, SUS, waterfall.

\section{INFORMATION SYSTEM OF SMALL AND MEDIUM ENTERPRISES GOVERNMENT OF BOYOLALI WEBISTE BASED}

\begin{abstract}
Boyolali Regency is one of 35 regencies / cities in Central Java that is pro-investment and has fewer units consisting of industry, micro small and medium enterprises. At present, the management of Boyolali Regency Government is still conducting conventional data collection. Despite the distance, the Department of Trade and Industry must recap data by visiting each sub-district in Boyolali Regency. In addition, there is no information media for the Boyolali Regency Small and Medium Enterprises that can be accessed by the general public. This research makes the Information System of Small and Medium Enterprises Government of Boyolali Website Based to facilitate the office to get industry data, the general public who has an industry can access it online so they can get help online, and makes this system as a medium for industrial promotion. This information system uses a framework with the PHP programming language, and a MySQL database. The software development method used is waterfall, in the design and manufacture of needs analysis design, application design, application coding, testing, and maintenance. Based on the results of black box testing, the system that has a menu of managing industrial data, managing member data, managing the industry recap, managing the submission of assistance and this system as a means of information media about the Small and Medium Enterprises based on SUS testing, the system gets a score of 70.58 which means the system is included in the good and acceptable category.
\end{abstract}

Keywords: black box, information systems, small and medium enterprises, SUS, Boyolali Regency, waterfall.

\section{PENDAHULUAN}

Kabupaten Boyolali adalah salah satu dari 35 Kabupaten atau Kota di Provinsi Jawa Tengah yang cukup potensial karena mempunyai sumber daya alam, tenaga kerja yang terampil, serta memiliki sektor perekonomian yang sangat baik karena di 
dukung oleh kebijakan pemerintah daerah yang pro investasi. Sehingga, sangat membantu tumbuh dan berkembangnya Industri Kecil Menengah (IKM). Dalam hal ini, pemerintah memiliki peran untuk mengatasi persoalan pengangguran, kemiskinan, dan kesenjangan antar sektor. Maka dari itu, keberadaan IKM sangatlah penting untuk tercapainya suatu dasar ekonomi yang kuat sehingga, sektor IKM mampu menyerap tenaga kerja yang cukup besar dan menjadi roda penggerak ekonomi yang baik [1]. Menurut data dari Dinas Perdagangan dan Perindustrian Kabupaten Boyolali (2019) jumlah industri yang ada di Kabupaten Boyolali ada kurang lebih 5.055 unit, yang terdiri dari industri mikro, kecil dan menengah. Klasifikasi yang terbesar adalah industri mikro kecil, karena modal usaha (investasi) yang dibutuhkan tidak besar. Disamping itu, teknologi yang digunakan juga sangat sederhana begitu pula dengan industri kecil menengah, Jenis industri kecil menengah cukup beragam serta tersebar diberbagai kecamatan. Produk yang dihasilkan selain bisa bersaing dengan produk dari daerah lain, juga sudah banyak diekspor ke manca negara.

Hasil observasi yang dilakukan penulis di Dinas Perdagangan dan Perindustrian (DISDAGPERIN) Kabupaten Boyolali menunjukan bahwa, belum adanya sistem yang terkomputerisasi, pendataan dan pendaftaran industri masih dilakukan secara manual dengan cara dinas mendatangi setiap kecamatankecamatan yang ada di Kabupaten Boyolali, dengan kasus ini pelaku industri juga enggan untuk mendaftarkan industrinya secara pribadi ke DISDAGPERIN. Selain itu, kurangnya promosi dan hubungan antara pelaku industri dengan DISDAGPERIN mengakibatkan lambannya perkembangan IKM yang ada di Kabupaten Boyolali.

Penelitian dibidang industri kecil menengah sudah banyak dilakukan salah satunya peneitian mengenai Usaha Kecil Menengah (UMKM). Dalam hal ini, UMKM dan IKM memiliki pengertian dan kriteria yang berbeda tetapi memiliki korelasi yang jelas antara UMKM dengan IKM. UMKM adalah sebuah usaha menjual kembali produk yang dihasilkan oleh industri, UMKM terbagi menjadi tiga jenis usaha yaitu usaha mikro, usaha kecil, dan usaha menengah. Sedangkan, IKM adalah sebuah usaha memproduksi produk dari bahan mentah menjadi bahan jadi. Keduanya sangat berperan bagi tumbuh dan berkembangnya perekonomian. Dalam penelitian sebelumnya, telah dilakukan rancang bangun sistem informasi yang dilengkapi dengan MAPS lokasi UMKM agar mempermudah mengetahui sebaran UMKM disetiap daerah [2]. Penelitian tersebut menggunakan XAMPP sebagai pembuatan server lokal dengan database $M y S Q L$ dengan fitur PHPMyAdmin yang tersedia didalamnya [3]. Pada perancangan sistem informasi ini menggunakan System Development Life Cycle (SDLC) dengan bahasa pemrograman PHP [4]. Hasil dari penelitian tersebut adalah terbangunnya sistem informasi guna pendataan IKM, pendataan IKM dapat di cetak berdasarkan komuditas, desa, kecamatan, tahun pendataan. Rekap data IKM tersebut berupa file Portable Data File (PDF) maupun dalam bentuk Ms. Excel [5]. Selain digunakan sebagai pendataan, Sistem Informasi tersebut dapat digunakan sebagai media promosi, agar produk-produk yang telah di produksi dapat dikenal oleh masyarakat umum [6]. pengembangkan aplikasi pemetaan penyebaran IKM berbasis android juga memiliki manfaat guna memberikan solusi kepada pengguna untuk melaporkan perkembangan dan persebaran IKM, serta aplikasi ini dilengkapi dengan Google Maps[7].

Penelitian ini berfokus pada Dinas Perdagangan dan Perindustrian Kabupaten Boyolali yang sebelumnya melakukan pendataan industri secara manual yang mengakibatkan lambannya proses pendataan, mengajukan proposal bantuan yang tidak sesuai dengan SOP dan kurangnya media promosi IKM Kabupaten Boyolali. Sehubungan dengan hal tersebut, penelitian ini bertujuan merancang bangun Sistem Informasi Industri Kecil Menengah Pemerintahan Kabupaten Boyolali berbasis Website yang berfungsi sebagai pendataan industri baru kepada dinas yang dilakukan oleh pelaku industri secara online, pengajuan proposal bantuan secara online yang dapat diajukan oleh pelaku industri sesuai SOP yang berlaku, dan sebagai media promosi IKM. Sistem ini diharapkan dapat mendukung proses operasional sehari-hari oleh DISDAGPERIN, pelaku industri, maupun masyarakat umum. Dalam sistem ini penulis menggunakan metode pengembangan SDLC waterfall dan framework laravel dengan bahasa pemrograman $P H P, H T M L$ dan $M Y S Q L$ sebagai database, serta penulis akan menguji sistem ini dengan metode pengujian black box dan pengujian System Usability Scale (SUS).

\section{METODE PENELITIAN}

Metode yang digunakan dalam mengembangkan Sistem Informasi Industri Kecil Menengah Pemerintahan Kabupaten Boyolali berbasis Website ini yaitu menggunakan metode System Developement Life Cycle (SDLC). SDLC adalah suatu proses pengembangan atau modifikasi perangkat lunak sistem dengan menggunakan model dan solusi yang digunakan oleh user untuk membangun sistem perangkat lunak sebelumnya (berdasarkan praktik terbaik atau metode yang telah teruji dengan baik)[8]. Dalam metode SDLC penulis menggunakan model waterfall yang mempunyai beberapa tahapan meliputi, analisis kebutuhan, desain, implementasi/koding, pengujian, 
pemeliharaan [9]. Adapun model metode waterfall ditunjukan pada Gambar 1.

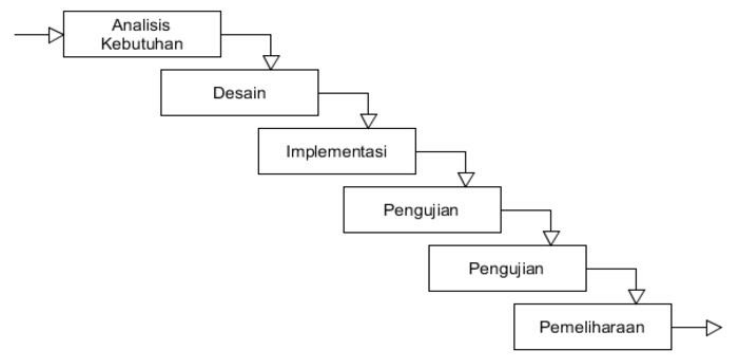

Gambar 1. Model Metode Waterfall

\subsection{Analisis Kebutuhan}

Tahap analisis dilakukan untuk memenuhi sifat program yang akan dikembangkan meliputi, user interface yang diinginkan dan fungsi fitur yang dibutuhkan. Tahap analisis berisi definisi tindakan perangkat untuk pengembangan. Biasanya, informasi yang diberikan adalah oleh konsumen[10]. Dalam tahap analisis, penulis melakukan wawancara dengan staff DISDAGPERIN Kabupaten Boyolali yaitu Bapak Aris. Dalam wawancara yang penulis lakukan, dapat disimpulkan bahwa sistem diharapkan mempunyai user interface yang sederhana agar mudah untuk dioperasikan. Selain itu, fitur-fitur yang dibutuhkan meliputi, kelola data member, kelola data industri, kelola artikel, kelola rekap data industi. Sistem juga diharapkan memuat informasi Industri Kecil Menengah yang ada di Kabupaten Boyolali. Terdapat tiga user dalam sistem yang akan dikembangkan. User pertama yaitu admin dari DISDAGPERIN yang bertugas memonitoring terhadap aktivitas pada sistem ini. User yang kedua adalah member, juga bertugas memonitoring data industri pribadi dan yang ketiga adalah user publik (masyarakat umum) selain hanya bisa mengakses tampilan sistem, masyarakat umum yang memiliki industri juga dapat melakukan pendaftaran online dengan syarat-syarat yang telah dinas tentukan.

\subsection{Desain}

Tahap desain yang dilakukan meliputi, usecase, diagram activity, dan database. Tahap desain tidak semua tentang antarmuka gaya tetapi terkait dengan desain algoritma, server, desain struktural, desain konsep, dan merancang arsitektur perangkat lunak. Aplikasi dan framework dirancang sesuai dengan kebutuhan spesifikasi tahap pertama[11].

\subsubsection{Usecase Diagram}

Desain usecase user DISDAGPERIN ditunjukan pada Gambar 2, usecase user member ditunjukan pada Gambar 3, dan usecase user publik ditunjukan pada Gambar 4.

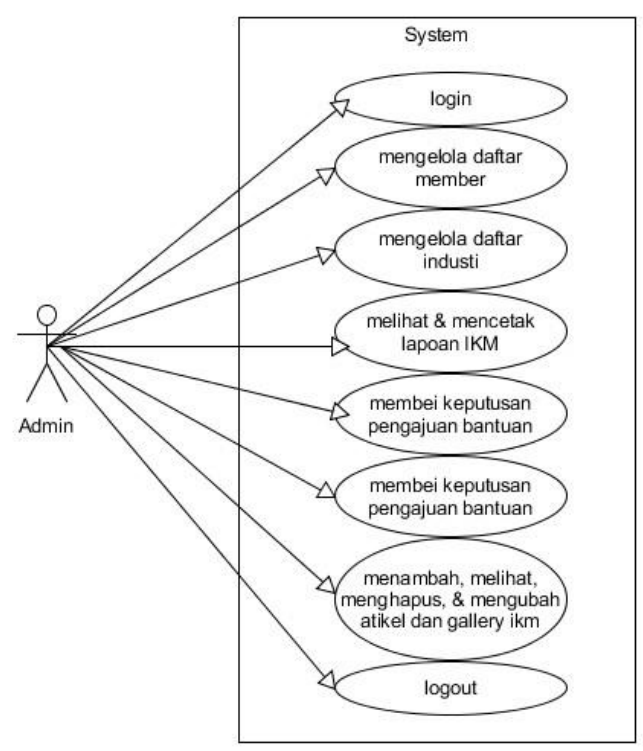

Gambar 2. Usecase Admin DISDAGPERIN

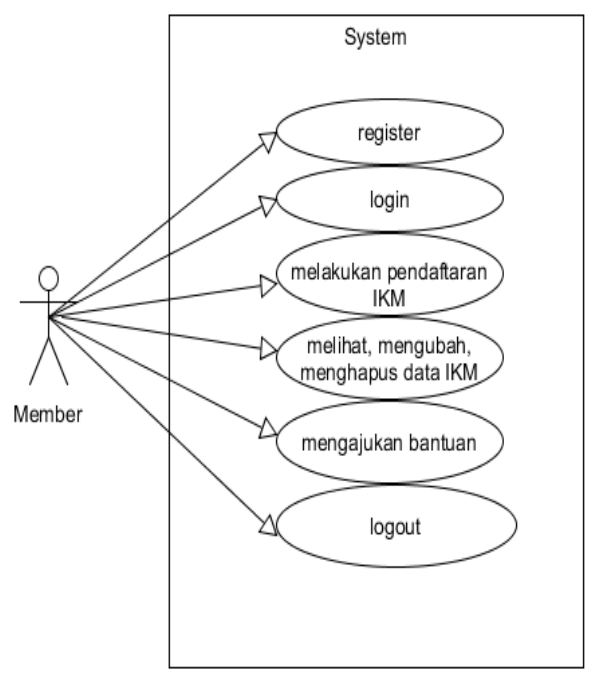

Gambar 3. Usecase User Member

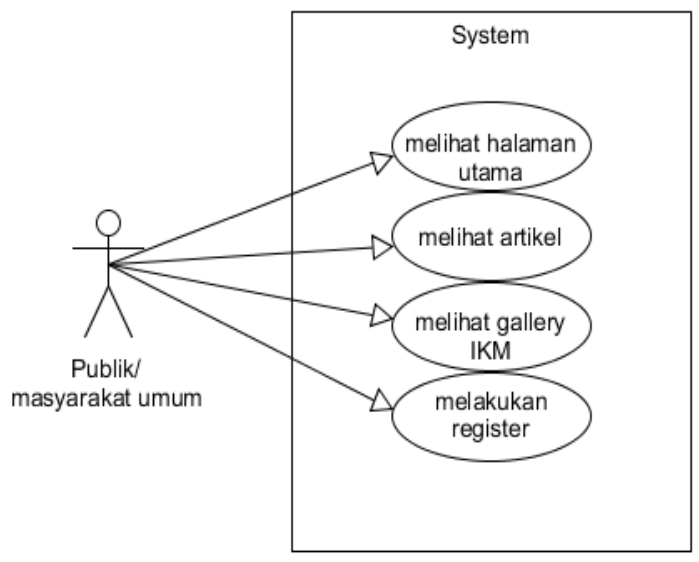

Gambar 4. Usecase Publik 


\subsubsection{Activity Diagram}

Activity Diagram adalah tipe khusus dari statechart yang berfokus pada suatu aktivitas- atau potongan-potongan proses yang sesuai dengan metode atau fungsi anggota dan aktivitas yang telah terjadi[12]. Adapun activity diagram ditunjukan pada Gambar 5 dan Gambar 6.

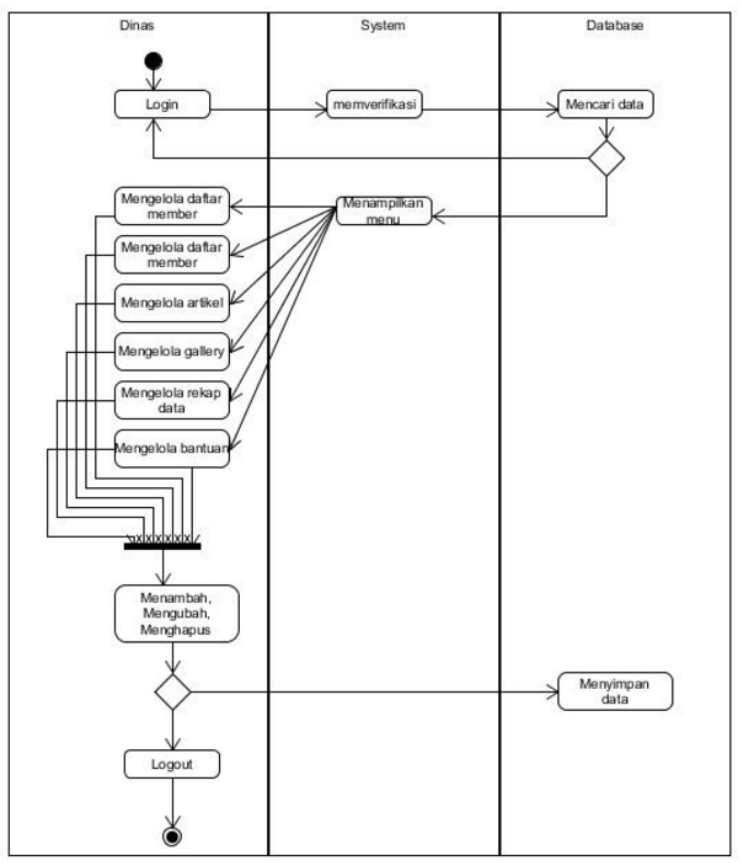

Gambar 5. Activity Diagram Admin

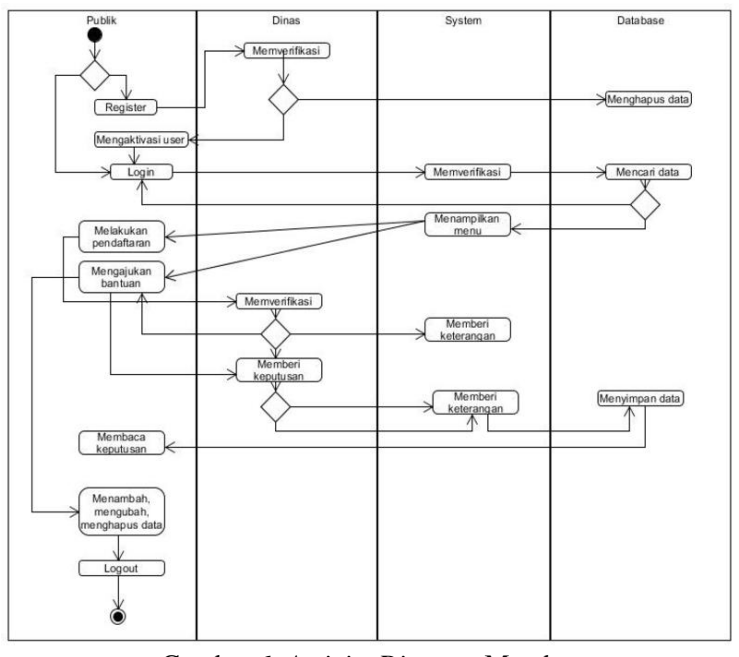

Gambar 6. Activity Diagram Member

\subsubsection{Rancangan Database}

Desain yang selanjutnya adalah desain database. Database dalam sistem ini memiliki 5 tabel dan diwujudkan dalam Entitiy Reletionship Diagram (ERD) fisik seperti yang ditunjukan pada Gambar 7.

\subsection{Implementasi}

Sistem Informasi Industri Kecil Menengah PEMKAB Boyolali Berbasis Web akan dibangun menggunakan bahasa pemrograman PHP (Hypertext Processor), dengan framework laravel. Laravel merupakan program perangkat lunak dengan sintaks yang elegan dan memiliki jangkauan luas fungsi seperti perlindungan, penyimpanan kata sandi, pengingat kata sandi, pengaturan ulang kata sandi, enkripsi, dan persetujuan [13]. Sedangkan database dalam sistem ini adalah MySQL. MySQL merupakan aplikasi basis data denagn konsep relasional yang memerlukan penyimpanan data, seperti data siswa, guru, mentor, jurnal konten dan portofolio konten [14].

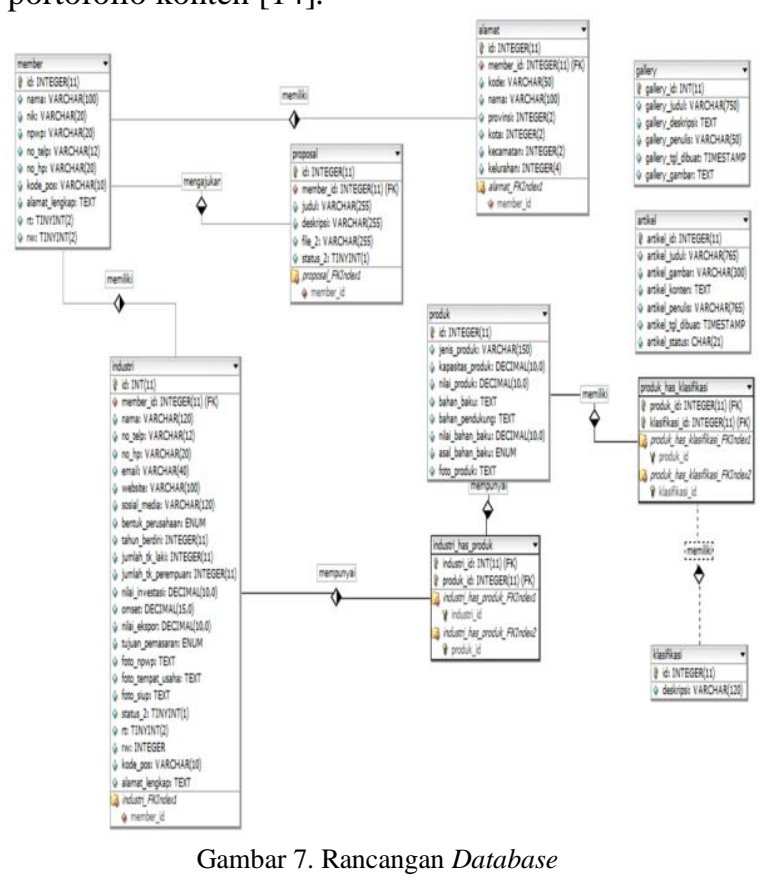

\subsection{Pengujian}

Dalam penelitian ini akan dilakukan pengujian dengan menggunakan metode black box dan System Usability Scale (SUS). Pengujian dengan metode black box digunakan untuk tes fungsionalitas input atau output dalam suatu perangkat lunak, sedangkan System Usability Scale (SUS) digunakan untuk menunjukan apakah pelanggan akan menganggap perangkat lunak tersebut mudah dimengerti dan dapat dioperasikan dengan benar [15].

\subsection{Pemeliharaan}

Tahap akhir dalam metode pengembangan waterfall adalah pemeliharaan. Sistem informasi Industri Kecil Menengah PEMKAB Boyolali berbasis website yang sudah jadi akan dijalankan serta dilakukan pemeliharaan. Setelah dijalankan dan dilakukan pemeliharaan maka akan dilakukan modifikasi perangkat lunak dengan memperbaiki kesalahan setelah digunakan dan dibuat dengan 
memperbaiki kesalahan-kesalahan sebelumnya, serta meningkatkan kinerja dan kualitas ataupun peningkatan fungsi program [11].

\section{HASIL DAN PEMBAHASAN}

Hasil penelitian menggunakan waterfall yang menghasilkan sebuah Sistem Informasi Industri Kecil Menengah Pemerintahan Kabupaten Boyolali Berbasis Website dengan melibatkan tiga user yaitu publik (masyarakat umum), member (pelaku industri), admin (dinas). Admin memiliki hak akses untuk mengolah data-data yang ada, kemudian member memiliki hak akses untuk mengubah data, menghapus data, menambah data dan sebagai monitoring industri yang telah terdata oleh dinas, serta publik memiliki hak akses untuk melakukan registrasi. Sedangkan pengujian sistem menggunakan pengujian Black box. Berikut adalah penjelasan dari hasil yang diperoleh dalam pembangunan sistem ini.

\subsection{Hasil Tampilan Sistem}

\subsubsection{Halaman Utama}

Halaman utama adalah halaman ketika publik (masyarakat umum) dapat melihat menu-menu yang tersedia dalam halaman utama. Pada halaman utama tersedia menu login dan pendaftaran. Selain itu masyarakat umum disajikan beberapa menu pada halaman utama seperti, menu artikel dan menu gallery. Halaman utama ditunjukan pada Gambar 8.

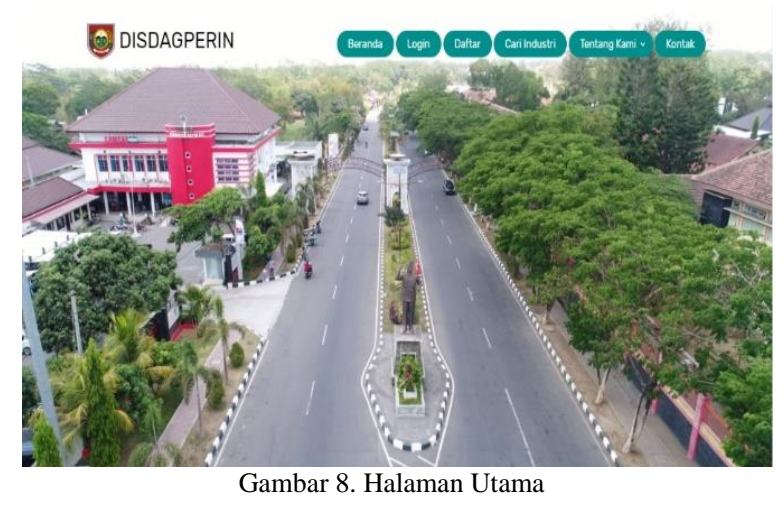

\subsubsection{Halaman Member}

Sebelumnya pada halaman utama terdapat menu login dan pendaftaran, apabila masyarakat umum memiliki industri dan belum melakukan pendataan kepada dinas maka harus melakukan regristrasi user. Setiap regristrasi otomatis beralih ke halaman login. Setelah login, user akan diarahkan ke halaman member. Halaman member berisi menu industri dan produk yang berisi kolom pendaftaran industri dan terdapat menu proposalku. Apabila industri telah disetuji oleh DISDAGPERIN, maka member dapat mengajukan bantuan di menu proposalku. Halaman member industri dan produk ditunjukan pada Gambar 9 dan halaman member proposalku ditunjukan pada Gambar 10.

\subsubsection{Halaman Admin}

Admin pada halaman admin dapat memasukan dan mengelola data meliputi kelola daftar member, kelola daftar industri, kelola daftar artikel, kelola daftar gallery, kelola pengajuan bantuan. Pada halaman admin semua data yang di input dan dikelola member akan divalidasi atas persetujuan DISDAGPERIN. Selain itu, admin dapat mencetak semua rekap industri maupun rekap industri setiap kecamatan, admin juga dapat melihat detail industri. menu validasi industri pada menu daftar industri ditunjukan pada Gambar 11.

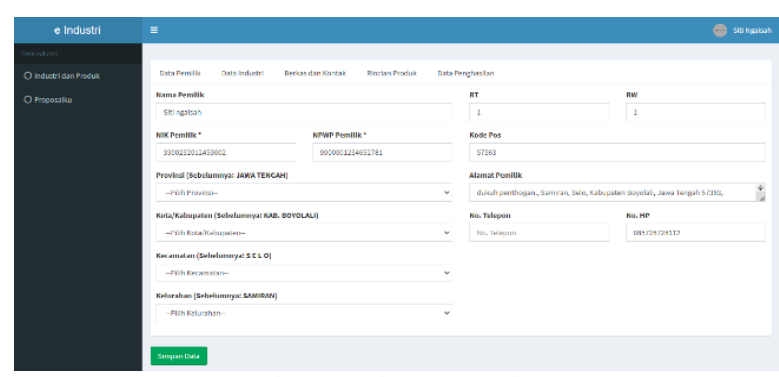

Gambar 9. Halaman Member

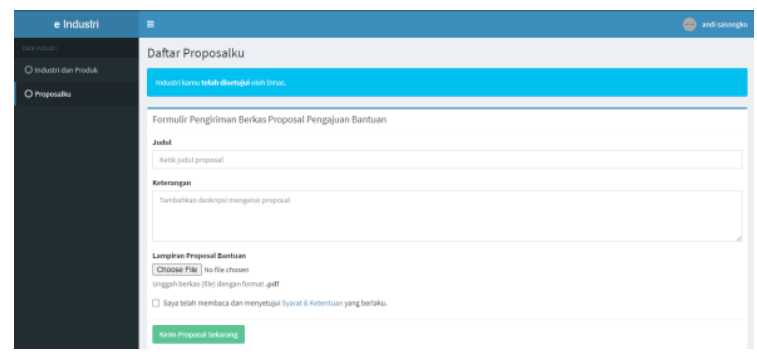

Gambar 10. Halaman Member Proposalku

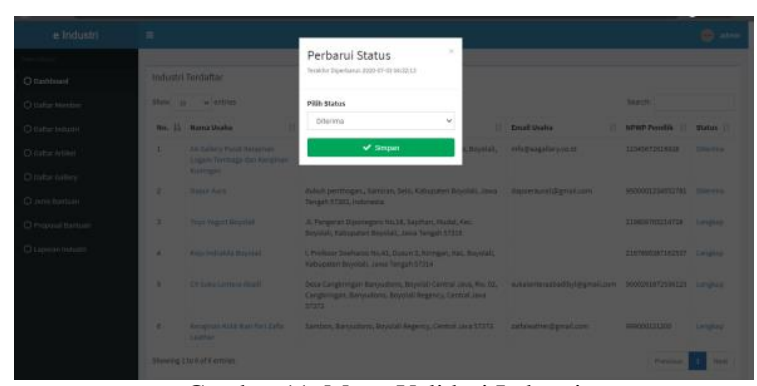

Gambar 11. Menu Validasi Industri

Halaman admin memiliki beberapa menu diantaranya menu proposal bantuan. Pada menu proposal bantuan, member yang sudah divalidasi admin dapat mengajukan permohonan bantuan sesuai SOP DISDAGPERIN. Pengajuan hanya dapat dilakukan 2 tahun sekali, sebelum proposal pengajuan bantuan divalidasi admin dapat mencetak proposal dalam bentuk PDF di kolom lampiran. Menu validasi proposal bantuan ditunjukan pada 
Gambar 12 dan cetak proposal bantuan ditunjukan pada Gambar 13.

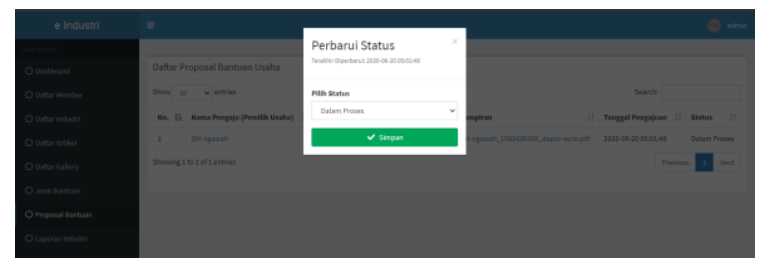

Gambar 12. Menu Validasi Proposal Bantuan

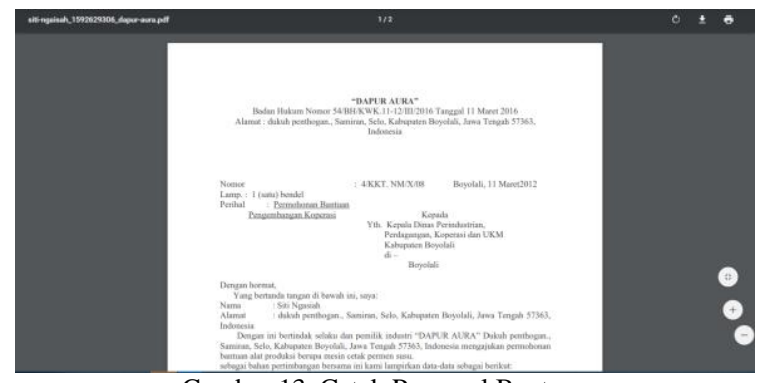

Gambar 13. Cetak Proposal Bantuan

Selain itu terdapat menu laporan industri yang berisi rekap data industri kecil menengah yang masuk. Menu laporan industri admin dapat mencetak laporan industri sesuai kebutuhan. Cetak rekap laporan industri dapat ditunjukan pada Gambar 14 dan hasil cetak laporan industri dapat ditunjukkan pada Gambar 15.

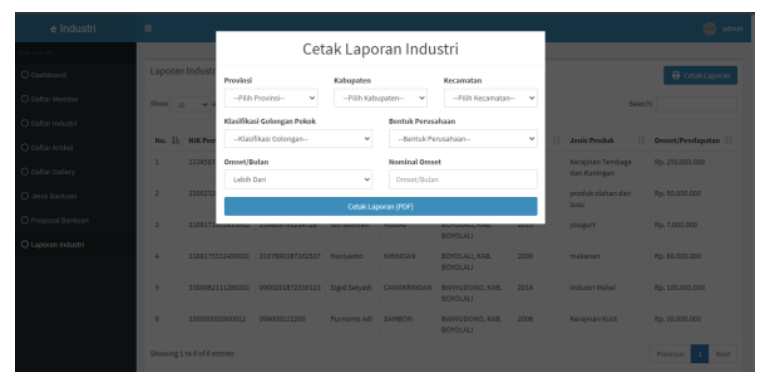

Gambar 14. Cetak Laporan Industri

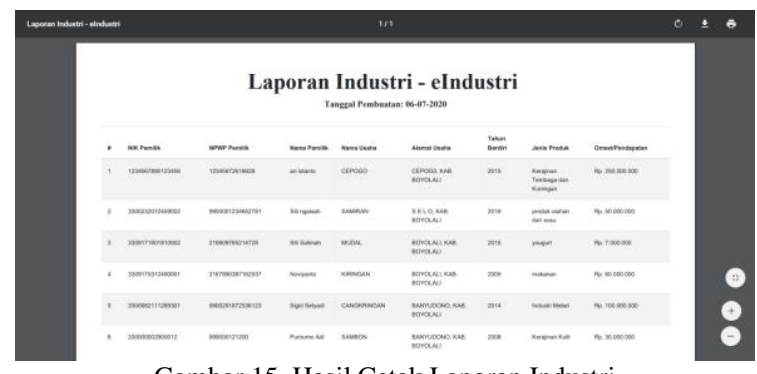

Gambar 15. Hasil Cetak Laporan Industri

\subsection{Pengujian}

\subsubsection{Blackbox}

Pengujian black box merupakan teknik pengembangan perangkat lunak yang digunakan untuk mengevaluasi fungsionalitas sistem. Pengujian kotak hitam berfokus pada input untuk sistem dan output yang diharapkan untuk setiap input. Metode pengujian ini didasarkan pada persyaratan dan spesifik perangkat lunak[16]. Sesuai dengan hasil pengujian yang telah dilakukan, dapat disimpulkan bahwa semua fitur fungsional dapat berjalan dengan baik, seperti penjelasan pada Tabel 1 .

Table 1. Hasil Pengujian Black box

\begin{tabular}{|c|c|c|c|c|}
\hline $\begin{array}{c}\text { Bagian } \\
\text { Pengujia } \\
\mathbf{n}\end{array}$ & $\begin{array}{c}\text { Fungsi } \\
\text { yang di } \\
\text { uji }\end{array}$ & Input & Output & Status \\
\hline \multicolumn{5}{|c|}{ Halaman Login } \\
\hline \multirow[t]{3}{*}{ Login } & \multirow[t]{2}{*}{$\begin{array}{l}\text { Menu } \\
\text { login } \\
\text { masuk } \\
\text { system }\end{array}$} & $\begin{array}{l}\text { Memasukka } \\
\mathrm{n} \text { username } \\
\text { dan } \\
\text { password } \\
\text { benr }\end{array}$ & $\begin{array}{l}\text { Menuju ke } \\
\text { halaman sesuai } \\
\text { dengan jenis } \\
\text { user }\end{array}$ & Sesuai \\
\hline & & $\begin{array}{l}\text { Memasukka } \\
\mathrm{n} \text { username } \\
\text { dan } \\
\text { password } \\
\text { salah }\end{array}$ & $\begin{array}{l}\text { Kembali ke } \\
\text { halaman login }\end{array}$ & Sesuai \\
\hline & & \multicolumn{2}{|c|}{ Halaman Admin } & \\
\hline \multirow[t]{2}{*}{$\begin{array}{l}\text { Menu } \\
\text { Data } \\
\text { Admin }\end{array}$} & $\begin{array}{l}\text { Menu } \\
\text { daftar } \\
\text { member }\end{array}$ & $\begin{array}{l}\text { Klik daftar } \\
\text { member }\end{array}$ & $\begin{array}{l}\text { Menampilan } \\
\text { data } \\
\text { member/pemili } \\
\text { k industri } \\
\text { sesuai yang } \\
\text { dimasukkan } \\
\text { member }\end{array}$ & Sesuai \\
\hline & $\begin{array}{l}\text { Menu } \\
\text { daftar } \\
\text { industri }\end{array}$ & $\begin{array}{l}\text { Klik daftar } \\
\text { industri, } \\
\text { klik status }\end{array}$ & $\begin{array}{l}\text { Menampilkan } \\
\text { perubahan } \\
\text { status validasi }\end{array}$ & Sesuai \\
\hline \multirow[t]{6}{*}{$\begin{array}{l}\text { Menu } \\
\text { data } \\
\text { admin }\end{array}$} & $\begin{array}{l}\text { Menu } \\
\text { daftar } \\
\text { industri }\end{array}$ & $\begin{array}{l}\text { Klik cetak } \\
\text { laporan, } \\
\text { mengisikan } \\
\text { data data } \\
\text { yang telah } \\
\text { tertera } \\
\text { Klik nama } \\
\text { usaha }\end{array}$ & $\begin{array}{l}\text { Menampilkan } \\
\text { rekap } \\
\text { ndustry dan } \\
\text { dapat dicetak } \\
\text { dalam bentuk } \\
p d f \\
\text { Menampilkan } \\
\text { detail industri }\end{array}$ & Sesuai \\
\hline & & $\begin{array}{l}\text { Menu daftar } \\
\text { artikel }\end{array}$ & $\begin{array}{l}\text { Klik daftar } \\
\text { artikel }\end{array}$ & $\begin{array}{l}\text { Menambah, } \\
\text { mengubah, } \\
\text { menghapus } \\
\text { data artikel }\end{array}$ \\
\hline & & $\begin{array}{l}\text { Menu daftar } \\
\text { gallery }\end{array}$ & $\begin{array}{l}\text { Klik daftar } \\
\text { gallery }\end{array}$ & $\begin{array}{l}\text { Menambah, } \\
\text { mengubah, } \\
\text { menghapus, } \\
\text { gallery }\end{array}$ \\
\hline & & $\begin{array}{l}\text { Menu } \\
\text { proposal } \\
\text { bantuan }\end{array}$ & $\begin{array}{l}\text { Klik proposal } \\
\text { bantuan, klik } \\
\text { nama pengaju }\end{array}$ & $\begin{array}{l}\text { Menampilka } \\
\text { n perubahan } \\
\text { status } \\
\text { validasi } \\
\text { pengajuan } \\
\text { bantuan }\end{array}$ \\
\hline & & & Klik lampiran & $\begin{array}{l}\text { Mencetak } \\
\text { proposal } \\
\text { yang telah } \\
\text { dimasukkan } \\
\text { user }\end{array}$ \\
\hline & & \multicolumn{2}{|c|}{ Halaman Member } & \\
\hline \multirow[t]{2}{*}{$\begin{array}{l}\text { Menu } \\
\text { Data } \\
\text { Member }\end{array}$} & $\begin{array}{l}\text { Menu } \\
\text { industri } \\
\text { dan } \\
\text { produk }\end{array}$ & $\begin{array}{l}\text { Klik menu } \\
\text { industri dan } \\
\text { produk }\end{array}$ & $\begin{array}{l}\text { Menambah, } \\
\text { mengubah, } \\
\text { menghapus, } \\
\text { menyimpan } \\
\text { data pemilik } \\
\text { dan industri }\end{array}$ & Sesui \\
\hline & $\begin{array}{l}\text { Menu } \\
\text { roposalk } \\
\mathrm{u}\end{array}$ & $\begin{array}{l}\text { Klik menu } \\
\text { proposalku }\end{array}$ & $\begin{array}{l}\text { Memasukkan } \\
\text { Prop Bantuan }\end{array}$ & Sesuai \\
\hline
\end{tabular}




\subsubsection{System Usability Scale}

Setelah dilakukan pengujian black box, selanjutnya dilakukan pengujian kedua yaitu dengan metode System Usability Scale (SUS). Sistem ini diujikan kepada 30 orang yang merupakan pelaku industri baru, masyarakat umum, dan admin DISDAGPERIN yang kemudian diberikan kuesoner untuk diisi pendapat dari pernyataan seputar fiturfitur sistem seperti Tabel 2 [17].

Tabel 2. Pernyataan Pengujian SUS

\begin{tabular}{cl}
\hline No & \multicolumn{1}{c}{ Pernyataan } \\
\hline 1 & Saya pikir saya akan sering menggunakan sistem ini \\
2 & Saya merasa kesulitan menggunakan sistem ini \\
3 & Saya pikir sistem ini mudah digunakan \\
4 & Saya perlu bantuan orang lain atau teknisi untuk menggunakan \\
& sistem ini \\
5 & Saya merasa fitur pada sistem ini berjalan dengan baik \\
6 & Saya merasa ada banyak yang tidak konsisten pada sistem ini \\
7 & Saya merasa orang lain akan cepat memahami dalam \\
8 & menggunakan sistem ini \\
9 & $\begin{array}{l}\text { Saya merasa sistem ini membingungkan } \\
\text { Saya yakin dapat menggunakan sistem ini }\end{array}$ \\
& Saya perlu waktu untuk membiasakan diri sebelum menggunakan \\
& sistem ini
\end{tabular}

Masing masing pernyataan di hitung berdasarkan pilihan responden yaitu SS = Sangat Setuju (nilai 5); $\mathrm{S}=$ Setuju (nilai 4); $\mathrm{N}=$ Netral (nilai 3); KS = Kurang Setuju (nilai 2); STS = Sangat Tidak Setuju (nilai 1). Dalam perhitungan SUS terdapat beberapa aturan dalam perhitungan skor pada kuesioner. Aturan pertama, pernyataan bernomor ganjil, nilai dari pengguna akan dikurangi 1. Aturan kedua, peryataan bernomor genap, nilai didapatkan dari nilai 5 dikurangi nilai yang telah didapat oleh pengguna. Aturan ketiga, skor SUS didapat dari hasil nilai setiap pernyataan kemudian dikali 2,5. Perhitungan SUS ditunjukkan pada Persamaan 1.

Skor SUS $=((\mathrm{R} 1-1)+(5-\mathrm{R} 2)+(\mathrm{R} 3-1)+(5-$ $\mathrm{R} 4)+(\mathrm{R} 5-1)+(5-\mathrm{R} 6)+(\mathrm{R} 7-1)+(5-\mathrm{R} 8)+$ $(\mathrm{R} 9-1)+(5-\mathrm{R} 10)) * 2.5$

Dari skor SUS yang didaapat, sistem dapat dinyatakan acceptable (dapat diterima) atau not acceptable (tidak dapat diterima). Maka dapat dilakukan dengan mencocokan nilai hasil dari pengujian dengan ketentuan penilaian sesuai pada Gambar 16 [18].

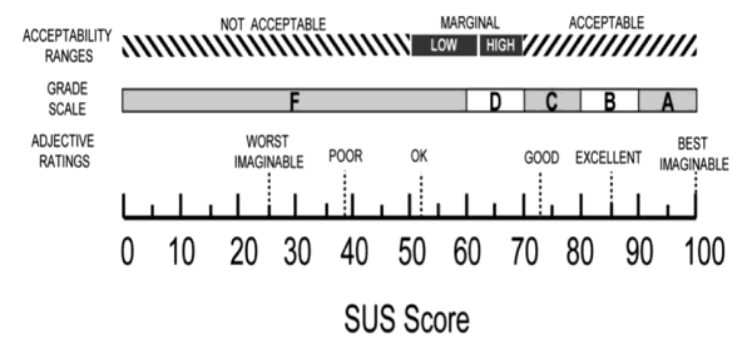

Setelah dilakukan penyebaran kuesioner kepada responden, maka diperoleh hasil perhitungan seperti pada Table 3 berikut.

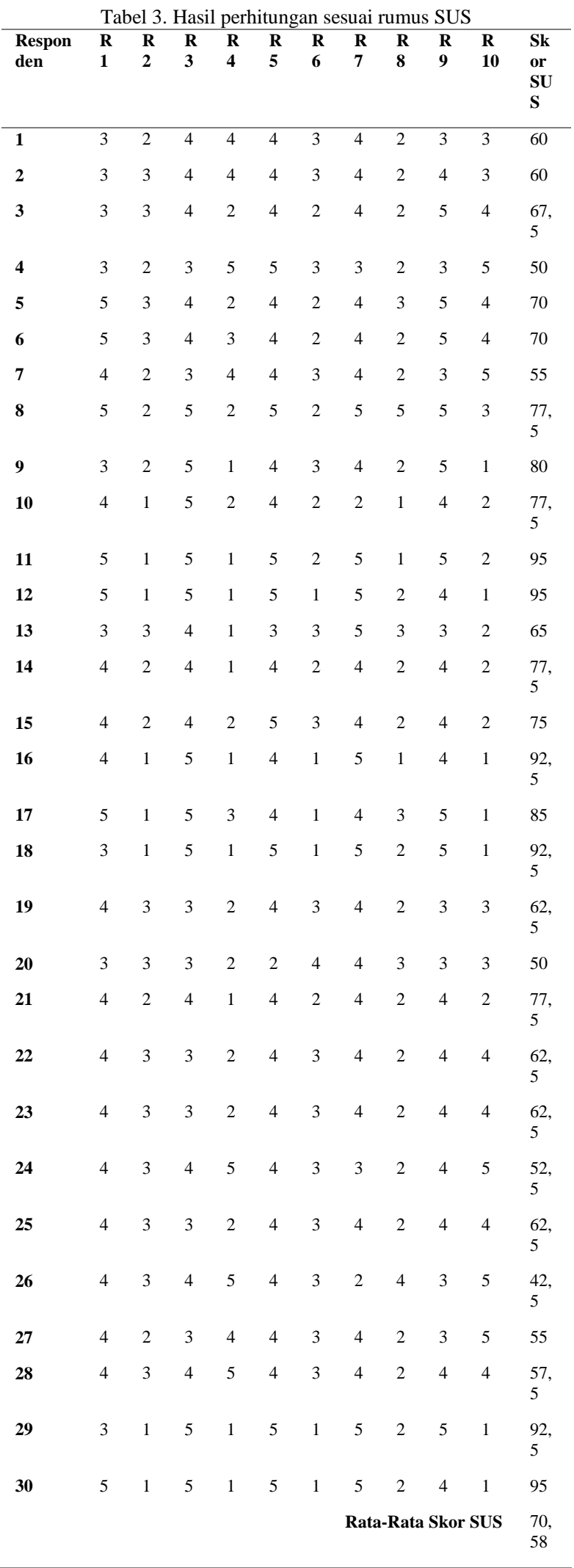


Dari data pengujian Table 3, penyebaran responden terbagi menjadi 4 responden yaitu, sebagai staf DISDAGPERIN, admin, masyarakat umum dan pelaku IKM. Skor SUS yang didapat sebesar 70,58 dan dengan ini dapat disimpulkan bahwa Sistem Informasi Industri Kecil Menengah Pemerintahan Kabupaten Boyolali Berbasis Website termasuk dalam kategori baik dan dapat diterima.

\section{KESIMPULAN}

Berdasarkan hasil uji black box, sistem yang dibuat mempunyai fitur fungsional sesuai dengan apa yang diharapkan. Sistem ini memiliki fitur kelola data industri, rekap laporan industri, kelola artikel, kelola gallery, kelola pengajuan bantuan yang diajukan oleh setiap member atau pemilik industri yang telah disetujui oleh DISDAGPERIN serta sistem ini menjadi sebuah sistem yang menyediakan informasi seputar Industri Kecil Menengah. Berdasarkan uji SUS, sistem ini mendapatkan skor sebesar 70,58 yang berarti sistem termasuk dalam kategori baik dan dapat diterima. Penulis berusaha membuat sistem sebaik mungkin. Namun kedepannya masih diperlukan pengembangan sistem yaitu penambahan fitur rekap data yang ditunjukkan menggunakan grafik atau diagram sejenisnya sehingga sistem informasi industri kecil menengah ini dapat memiliki fitur yang lebih kompleks.

\section{DAFTAR PUSTAKA}

[1] D. Mulyadi and E. W. Ramdani, "analisis strategi pemberdayaan industri," 2018.

[2] B. A. Abdullah, "Sistem informasi geografis sebaran umkm di kota cimahi," pp. 7-12, 2018.

[3] M. S. Gustavianto, A. Suprayogi, and A. P. Wijaya, "Jurnal Geodesi Undip Januari 2016," vol. 5, pp. 49-56, 2016.

[4] L. A. Utami and M. Kom, "Sistem informasi Penjualan Kerajinan Tempurung Kelapa Berbasis Web pada Butik," vol. 2, no. April 2018, pp. 98-104, 2019.

[5] E. Susena et al., "Perancangan sistem informasi manajemen pendataan industri kecil dan menengah di kapupaten sragen," vol. 5, pp. 45-51, 2018.

[6] Kasmawi, Mansur, and D. A. Fitri, "Sistem Informasi Promosi Produk: Studi Pada Usaha Kecil Menengah Kota Bengkalis," J. Teknol. Inf. Komun. Digit. Zo., vol. 9, pp. 59-70, 2018.

[7] I. Maita and Nurhikmah, "Aplikasi pemetaan penyebaran industri kecil dan menengah di pekanbaru berbasis android 1,2," vol. 4, no. 1, pp. 60-66, 2018.

[8] N. Hidayati, "Penggunaan Metode Waterfall Dalam Rancang Bangun Sistem Informasi
Penjualan," vol. 3, no. 1, pp. 1-10, 2019.

[9] P. Supriya, M. Salve, P. Syed, N. Samreen, and P. N. Khatri-valmik, "A Comparative Study on Software Development Life Cycle Models," pp. 696-700, 2018.

[10] A. Alshamrani and A. Bahattab, "A Comparison Between Three SDLC Models Waterfall Model , Spiral Model, and Incremental / Iterative Model," vol. 12, no. 1, pp. 106-111, 2015.

[11] W. Hardyanto, A. Purwinarko, I. M. Sudana, and E. Supraptono, "Model Development of Management Information System of Internship," no. January, 2018.

[12] H. A. Mumtahana, S. Nita, and A. W. Tito, "khazanah informatika Pemanfaatan Web ECommerce untuk Meningkatkan Strategi Pemasaran," vol. 3, no. 1, pp. 6-15, 2017.

[13] E. S. Soegoto, "Implementing Laravel framework website as brand image in higher- education institution Implementing Laravel framework website as brand image in," 2018.

[14] M. S. et Al, "Implementation of Sharing Knowledge Management in Internship Program Using Web-Based Information System Implementation of Sharing Knowledge Management in Internship Program using Web-based Information System,” 2018.

[15] B. Pramitasari and Nurgiyatna, "Sistem Informasi Unit Kegiatan Mahasiswa Marching Band Universitas Muhammadiyah Surakarta Berbasia Web," J. Emit., vol. 18, no. 01, pp. 59-65, 2019.

[16] A. Verma, A. Khatana, and S. Chaudhary, "A Comparative Study of Black Box Testing and White Box Testing International Journal of Computer Sciences and Engineering Open Access A Comparative Study of Black Box Testing and White Box Testing," no. July, 2019.

[17] J. R. Lewis, "Item Benchmarks for the System Usability Scale," vol. 13, no. 3, pp. 158-167, 2018.

[18] A. Bangor, T. Staff, P. Kortum, J. Miller, and T. Staff, "Determining What Individual SUS Scores Mean: Adding an Adjective Rating Scale," vol. 4, no. 3, pp. 114-123, 2009. 